\title{
Resin-Based Composite
}

National Cancer Institute

\section{Source}

National Cancer Institute. Resin-Based Composite. NCI Thesaurus. Code C52586.

A dental restorative material made up of disparate or separate parts (e.g., resin and quartz particles). 